\title{
Skin and bubble formation in films made of methyl nanocellulose, hydrophobically modified ethyl(hydroxyethyl)cellulose and microfibrillated cellulose
}

\author{
Johanna Lyytikäinen (D) Maria Morits • Monika Österberg • Isto Heiskanen • \\ Kaj Backfolk
}

Received: 9 June 2020/Accepted: 26 October 2020/Published online: 13 November 2020

(C) The Author(s) 2020

\begin{abstract}
The use of nanomaterials and polymers from renewable resources is important in the search for sustainable alternatives to plastic-based packaging materials and films. In this work, self-supporting thin films prepared from derivatized and non-derivatized nanocellulose and cellulose derivatives were studied. The effect of drying temperature on the film-forming behavior of compositions comprising hydrophobically modified ethyl(hydroxyethyl)cellulose (EHEC), native microfibrillated cellulose (MFC) and nanocellulose made from methyl cellulose was determined. The interaction between the components was assessed from viscosity measurements made at different temperatures, the result being linked to a thermal-dependent association during liquid evaporation, and the subsequent barrier and film-forming properties. The effect of temperature on suspensions was clearly different between the materials, confirming that there were differences in interaction and association
\end{abstract}

J. Lyytikäinen $(\bowtie) \cdot$ K. Backfolk

School of Energy Systems, Packaging Technology, Lappeenranta-Lahti University of Technology LUT, P.O. Box 20, 53851 Lappeenranta, Finland

e-mail: Johanna.Lyytikainen@lut.fi

M. Morits · M. Österberg

Department of Bioproducts and Biosystems, School of Chemical Engineering, Aalto University, P.O. Box 16300, 00076 Aalto, Finland

I. Heiskanen · K. Backfolk

Stora Enso Oyj, 55800 Imatra, Finland between EHEC-MFC and methyl nanocelluloseMFC compositions. The amphiphilic EHEC affected both the suspension homogeneity and the film properties. Air bubbles were formed under certain conditions and composition particularly in MFC films, dependent on the drying procedure. The presence of air bubbles did not affect the oxygen transmission rate or the oil and grease resistance. An increasing amount of MFC improved the oxygen barrier properties of the films.

Keywords Barrier - Hydrophobically modified ethyl(hydroxyethyl)cellulose · Methyl nanocellulose · MFC

\section{Introduction}

Fossil-based polymers are used in packaging applications because of their high barrier properties and low manufacturing costs, but environmental concerns have increased the need to develop renewable materials for barrier applications (Lavoine et al. 2012) and interest in the utilization of cellulosic materials for barrier applications has grown considerably.

The barrier properties of microfibrillated cellulose (MFC) have been studied widely. During dewatering and drying, the fibrils form a dense network due to the strong interaction between the fibrils. The dense network and the crystalline regions of MFC hinder 
other molecules such as oxygen from penetrating through the film (Syverud and Stenius 2009; Lavoine et al. 2012; Österberg et al. 2013). The barrier properties and strength of MFC films can thus provide an alternative for fossil-based barrier materials.

Several publications have demonstrated that it is possible to achieve high oxygen barrier properties with MFC films. The oxygen transmission rate (OTR) of MFC films is low under dry conditions due to the dense network, but it increases with increasing relative humidity (Aulin et al. 2010; Österberg et al. 2013; Herrera et al. 2017), because the increase in relative humidity weakens the hydrogen bonds and the structure of the cellulose network is loosened. The crystalline regions are however impermeable to water and a lower OTR can therefore be achieved with nanocellulose films at high relative humidities (Herrera et al. 2017; Solala et al. 2018). The water vapor transmission rate (WVTR) and water sorption of MFC are high due to the amorphous regions of the cellulose and they increase with increasing relative humidity (Aulin et al. 2010; Tammelin et al. 2015), so that MFC is a poor or only moderate water vapor barrier.

In practical applications, the barrier properties should withstand a relative humidity of $50 \%$ or higher and the barrier properties can be improved by surface modification of the MFC. Various ways to reduce the moisture sensitivity have been proposed, such as cross-linking (Herrera et al. 2017), the use of various coatings (Debeaufort et al. 2000; Spence et al. 2011; Hay et al. 2018) or post-curing. For example, both esterification and acetylation of MFC increase the hydrophobicity through surface modification, and TEMPO-oxidization of MFC enhances the gas barrier of the MFC films (Fukuzumi et al. 2009; Rodionova et al. 2011, 2013; Vuoti et al. 2013). The hydrophobization has a greater effect on the absorption of water by the MFC film than on its WVTR value. It is suggested that the volume and size of the pores in the film affect the WVTR value (Solala et al. 2018).

A post-thermal treatment above $100{ }^{\circ} \mathrm{C}$ of TEMPO-oxidized films and cellulose nanofibril films has been found to improve the oxygen and water vapor barrier properties due to changes in porosity and crystallinity. In addition, increasing the treatment temperature reduced the oxygen and water vapor transmission rates. Sharma et al. (2014), Xia et al. (2018) Österberg et al. (2013) reported similar effects when using hot pressing on nanofibrillated cellulose films.

In cellulose derivatization, the structure of the cellulose is chemically modified through hydroxyl groups in order to modify for example the solubility and rheological properties and the strength and barrier properties in the films (Jain et al. 2013; Paunonen 2013). For example, methyl cellulose films are transparent and they are good oxygen barriers but poor water vapor barriers (Paunonen 2013). Ethyl(hydroxyethyl)cellulose (EHEC) is a cellulose derivative which can be modified hydrophobically to increase its viscosity due to its self-associative behavior through its hydrophobic regions. The interaction between EHEC and surfactants is known to affect the cloud point and viscosity of the EHEC-surfactant solution (Thuresson and Lindman 1997). The barrier properties of cellulose derivatives such as hydroxypropyl methylcellulose and methyl cellulose have also been studied but, to our knowledge, neither ethyl(hydroxyethyl)cellulose nor methyl nanocellulose nor their combination with microfibrillated cellulose has been studied. Especially hydrophobically modified cellulose polymers are claimed to have higher moisture and water vapor resistance, whereas introduction of hydrophobic groups requires more research regarding the temperature dependence during film formation and water release during the dehydration process.

In the present work, the effect of drying temperature and solution composition on the film formation and barrier properties of EHEC, MFC or methyl nanocellulose-containing films were studied. The viscosity was measured in order to confirm interaction between the components. Oxygen barrier measurements were made to evaluate the film properties, supported with AFM and SEM imaging and surface energy measurements in order to determine the surface characteristics of the cast films.

\section{Materials and methods}

Solutions with different proportions of microfibrillated cellulose (Celish KY100G, Daicel FineChem Ltd.) or methyl nanocellulose (MeCellosic acid, MCA, Innotech Materials) and hydrophobically modified ethyl(hydroxyethyl)cellulose, (Bermocoll EHM 200, AkzoNobel Functional Chemicals AB) at 0.5 
$\mathrm{wt} \%$ concentration were cast in petri dishes and dried by evaporation at $23{ }^{\circ} \mathrm{C}$ and $50 \%$ relative humidity and at an elevated temperature $\left(50{ }^{\circ} \mathrm{C}\right)$. The grammage of the films was $30 \mathrm{~g} / \mathrm{m}^{2}$.

The viscosity of the solutions was determined with a Modular Compact Rheometer (MCR 302, Anton Paar) using the standardized $\mathrm{CC} 27$ measurement cylinder (cup mode) at different temperatures. The solutions were heated from 20 to $70{ }^{\circ} \mathrm{C}$ at a heating rate of $0.5{ }^{\circ} \mathrm{C} / \mathrm{min}$. The viscosity was measured using a shear rate of $50 \mathrm{~s}^{-1}$.

The oxygen transmission rate (OTR) of the films was determined at $23{ }^{\circ} \mathrm{C}$ and $50 \% \mathrm{RH}$ using the Mocon Ox-Tran Model 2/22 (Mocon, Minneapolis, USA). The reported OTR values are averages of three parallel measurements. The oil and grease resistance (OGR) was determined using the modified ISO 16532-1 standard, with any applied external pressure on the oil drop.

To evaluate the oil spreading on the surfaces, the contact angle of rapeseed oil with a drop volume of $5 \mu \mathrm{l}$ (Attension Theta Optical Tensiometer, Biolin Scientific $\mathrm{AB}$ ) was determined. Contact angles were measured using deionized water, ethylene glycol (VWR S.A.S. International) and diiodomethane (Alfa-Aesar $\mathrm{GmbH} \& \mathrm{Co} \mathrm{KG}$ ) with drop volumes of $1 \mu \mathrm{l}$ for diiodomethane and $3 \mu \mathrm{l}$ for deionised water and ethylene glycol in order to determine the surface energy. The measurements were made on samples at $23{ }^{\circ} \mathrm{C}$ and $50 \% \mathrm{RH}$. The contact angle values for the surface energy calculations were taken after one second after placing the drop. The surface energy $(\gamma)$ of the solid (s) was calculated using the van Oss acidbase approach based on the contact angles $(\theta)$ of two polar and one non-polar liquid (li) and the components: Lifschitz-van der Waals (LW), electron acceptor $(+)$ and electron donor (-) (Hejda et al. 2010):

$$
\left(1+\cos \theta_{i}\right) \gamma_{l i}=2\left(\sqrt{\gamma_{l i}^{L W} \gamma_{s}^{L W}}+\sqrt{\gamma_{l i}^{+} \gamma_{s}^{-}}+\sqrt{\gamma_{l i}^{-} \gamma_{s}^{+}}\right)
$$

FE-SEM images were obtained on uncoated cross sections using a FEI Nova NanoSEM 450 field emission scanning electron microscope (FE-SEM) equipped with a Schottky type emitter. The cross section was prepared with a Hitachi IM4000 broad ion beam cross section cutter. A copy paper was used as a carrier on which the sample was glued with a solventfree glue.

The microscope was operated in a low vacuum mode using a Gaseous Analytical Detector (GAD) and a field-free final lens mode. Both annular segments of the GAD were utilised. The detected signal consisted of back-scattered electrons (BSE). The working distance was set to $5.0 \mathrm{~mm}$ using an acceleration voltage of $5.0 \mathrm{kV}$. The scanning resolution was $1536 \times 1104$ pixels with a dwell time of $30 \mu \mathrm{s}$ per pixel. The spot size was adjusted to 4.0, resulting in a tabulated beam current of $170 \mathrm{pA}$. The final image was obtained by mapping and stitching individual FE-SEM images with an in-built automated image acquisition software, FEI MAPS 2.0.

For high-resolution topography imaging of composite dry films in the tapping mode (TM) and for quantitative nanomechanical mapping (QNM), a MultiMode 8AFM connected to a Nanoscope V controller (Bruker, Santa Barbara, CA) was used. High-resolution images were acquired in tapping mode in air using NCHV-A probes (Bruker) with a $\mathbf{J}$ scanner.

Mechanical properties measurements of the films were obtained using the PeakForce QNM mode in air. The PeakForce QNM was calibrated according to the PeakForce QNM User Guide, the deflection sensitivity being calibrated on a mica surface. The deflection sensitivity was $43.41 \mathrm{~nm} / \mathrm{V}$. Thermal tuning of the spring constant of the probe cantilever gave a value of $81 \mathrm{~N} / \mathrm{m}$. Polystyrene film with known modulus from PeakForce QNM sample kit was used to determine the tip radius which was ca. $70 \mathrm{~nm}$ at a deformation 4-5 nm. The DMT Young's modulus reported in the manuscript was calculated using Derjaguin, Muller, Toropov (DMT) model. Poisson's Ratio was 0.3. Samples were quite stiff, and consequently the Herzian fit model was used to calculate the sample moduli.

The TM images and QNM data were analyzed by NanoScopeAnalysis 1.5 software (Bruker). Flattening was applied only to height images. Roughness, adhesion and modulus values were calculated for the QNM images. Two PeakForce QNM readings of the EHEC and MFC samples were analyzed and three readings of all the other samples. Roughness values were calculated as root mean square $\left(R_{q}\right)$ averages of 
height deviations $\mathrm{z}_{i}$ taken from the mean image data plane values for $5 \times 5 \mu^{2}$ areas:

$R_{q}=\sqrt{\frac{\sum z_{i}^{2}}{N}}$

\section{Results and discussion}

Temperature dependence of viscosity

Figure 1 shows the viscosity of the 0.5 wt $\%$ EHECMFC and methyl nanocellulose-MFC solutions at different temperatures for different ratios of polymer to nanocellulose. The viscosity of the EHEC-MFC solutions decreased with increasing temperature and was strongly influenced by the concentration of EHEC (Fig. 1a). The viscosity of MFC suspensions also decreased with increasing temperature, which has also been reported elsewhere (Iotti et al. 2011). The initial viscosity of the EHEC-MFC solution decreased until the MFC content in the solution was $75 \%$. The MFC suspension had the highest initial viscosity, but E50 and E75 had almost the same initial viscosity, below that of both EHEC and MFC, indicating an interaction between the components especially with E50. The viscosity of the EHEC and E25 solution decreased with increasing temperature. The viscosity of the E25 solution was stable until temperature reached $35^{\circ} \mathrm{C}$ above which the viscosity started to decrease. The change in viscosity of MFC was greater at the beginning of the temperature range, but it was similar to that of E25 after the temperature reached $35{ }^{\circ} \mathrm{C}$.
The initial viscosity of methyl nanocellulose-MFC solutions increased with increasing MFC content (Fig. 1b). When the methyl nanocellulose-MFC solutions were heated, the viscosity decreased until the solutions reached a temperature at which the gelation started, which was seen as an increase in viscosity. A slight increase in viscosity of the Me25 solution was seen when the heating started. The viscosity remained unchanged until the temperature reached $30{ }^{\circ} \mathrm{C}$ after which it slowly decreased, although the change in viscosity was small. Before gelation, the viscosity remained unchanged, especially in the case of the Me50 solution. The gelation temperatures for Me75 and Me50 were 54 and $50{ }^{\circ} \mathrm{C}$, respectively, which may indicate that there is an interaction between methyl nanocellulose and MFC, since the gelation temperature should increase as the concentration of methyl nanocellulose decreases. The gelation of the Me25 solution started when the temperature reached $65^{\circ} \mathrm{C}$, due to a lower methyl nanocellulose content. Compared to MFC, the change in viscosity with Me25 is smaller.

Film formation and entrapped air bubbles

Films were cast from EHEC-MFC, EHEC-methyl nanocellulose and methyl nanocellulose-MFC solutions (Fig. 2). The transparency of the thin films differed significantly between the samples. In the case of MFC-containing films, the transparency of the films decreased with increasing amount of MFC (Fig. 2a, b, d). The EHEC-MFC films were less transparent when dried at a lower temperature (Fig. 2a). Pure EHEC and methyl nanocellulose films were transparent, but the
Fig. 1 Viscosity of the 0.5 wt\% EHEC-MFC (a) and methyl nanocellulose-MFC (b) mixtures at different temperatures. E and Me refer to EHEC and methyl nanocellulose, respectively and to their amounts in the mixtures
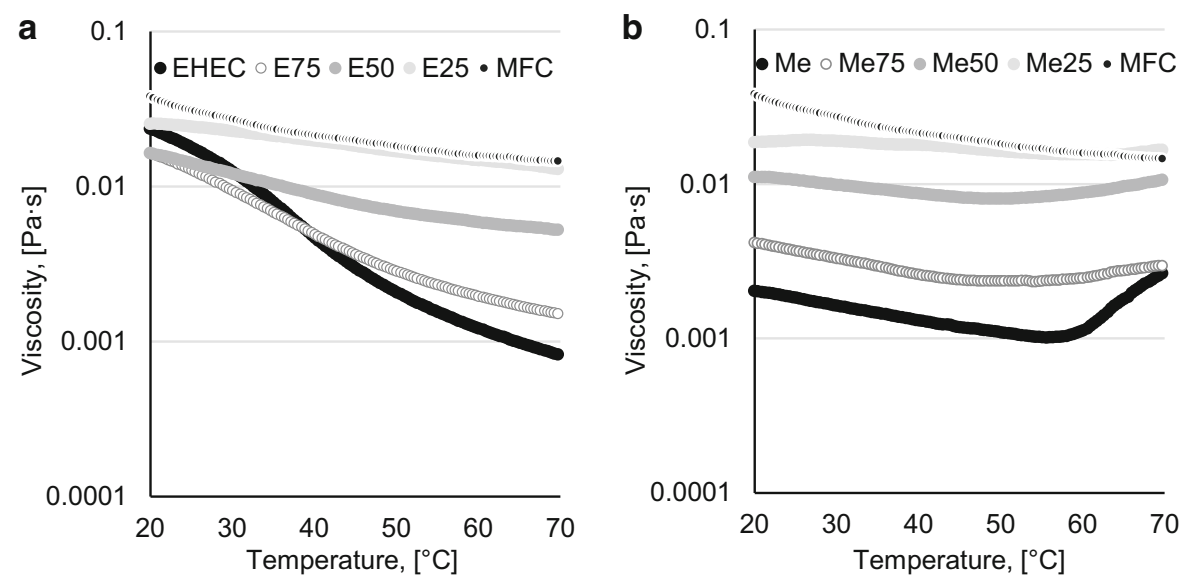
films containing both materials were less transparent the more methyl nanocellulose they contained (Fig. 2c).

Air bubbles occurred in some films, especially in EHEC-MFC and methyl nanocellulose-MFC films in a ratio of $25: 75$ when the films were dried at $50{ }^{\circ} \mathrm{C}$ (Fig. 3a, b). The surface roughness of the petri dish promoted the formation of air bubbles. When ethanol was used to pre-wet the surface before casting, bubbles were not observed in MFC film, which may be due to the changes in the surface energy or air removal from the surface. The air bubbles in the EHEC-MFC films were smaller and coalesced more than the bubbles in the methyl nanocellulose-MFC film. Some air bubbles were observed in the MFC films (Fig. 3c). The bubbles were more transparent in pure MFC film. In EHECMFC and methyl nanocellulose-MFC films with a ratio of 25:75, the bubbles were white, suggesting the presence of scattering fibrils in the surface, as was observed in the microscopic images. It seems that in the MFC film, the fibrils may have attached more to the air-water interface. Air bubbles were not observed when the EHEC-MFC films were dried at $23{ }^{\circ} \mathrm{C}$.

During drying the air bubbles coalesced, but they were stabilized especially in the EHEC-MFC film with a ratio of 25:72. The SEM image (Fig. 4) shows that the film containing air bubbles was continuous, which indicates that the surface of the film dried
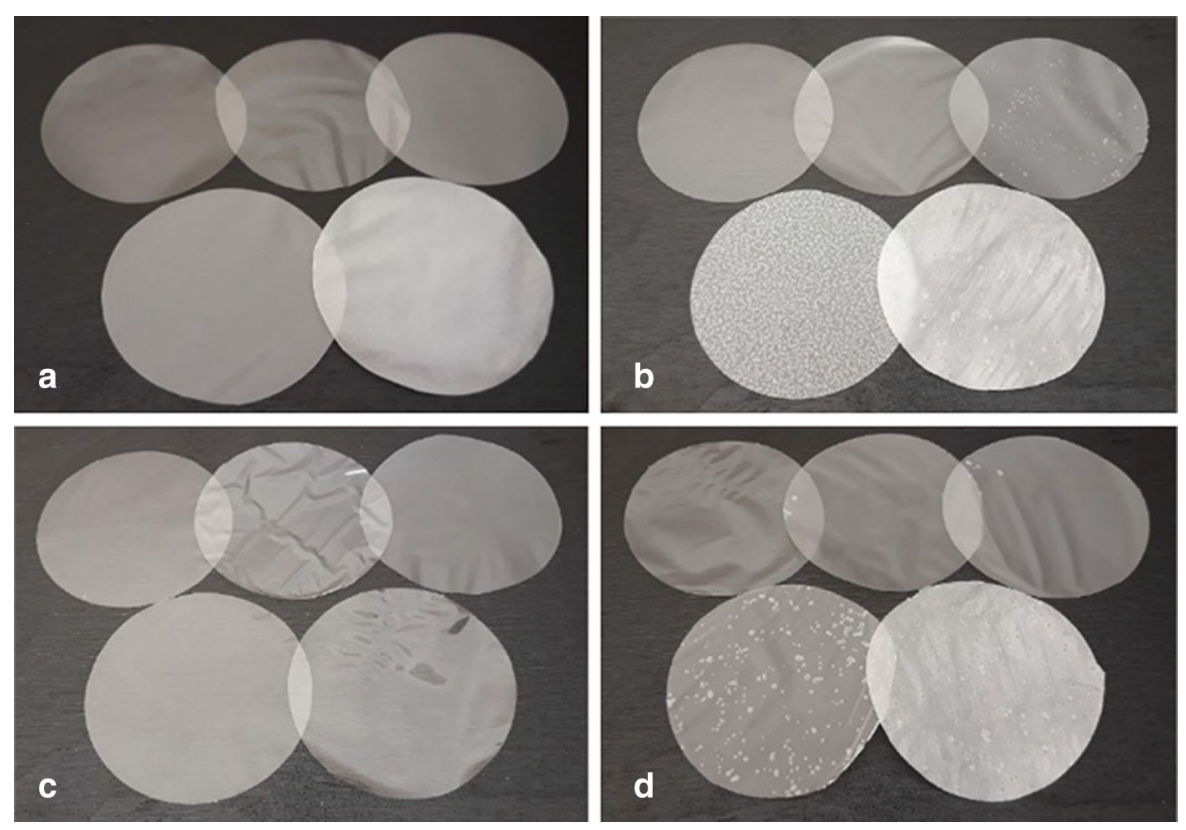

Fig. 2 EHEC-MFC films dried at $23{ }^{\circ} \mathrm{C}$ (a) and $50{ }^{\circ} \mathrm{C}$ (b). EHEC-methyl nanocellulose (c) and methyl nanocellulose-MFC (d) films dried at $50{ }^{\circ} \mathrm{C}$ with the ratios of 100:0, 75:25, 50:50 (upper row), 25:75 and 0:100 (lower row)
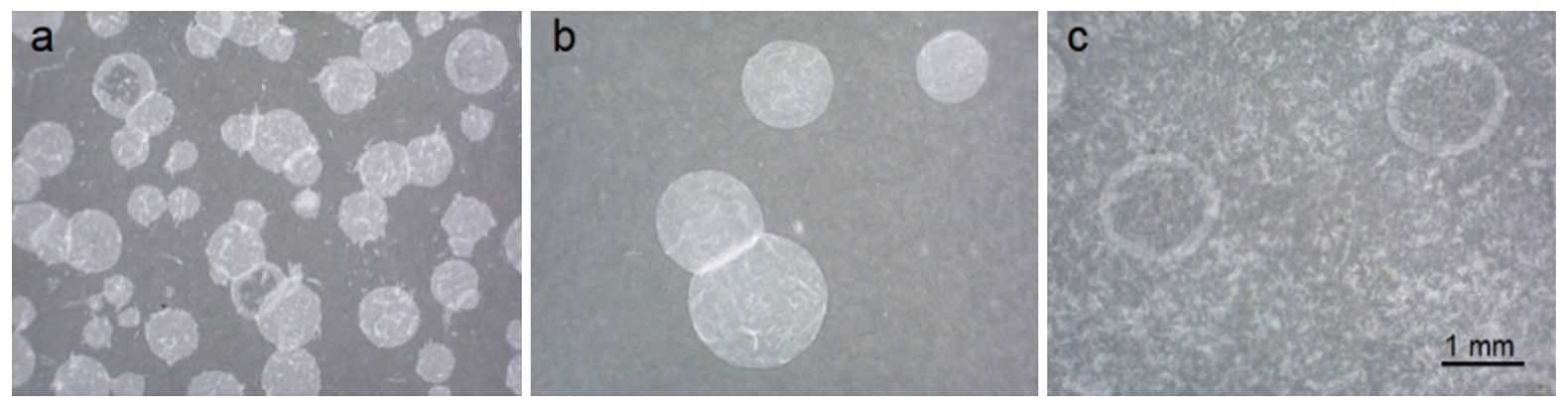

Fig. 3 EHEC-MFC (a), methyl nanocellulose-MFC (b), and MFC (c) films dried at $50{ }^{\circ} \mathrm{C}$. Mixtures were in a ratio of $25: 75$ 


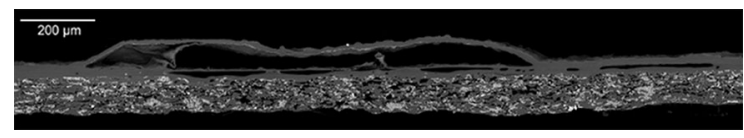

Fig. 4 SEM-image of a bubble in the EHEC-MFC film. A copy paper was used as a supportive layer for the sample

rapidly at a high temperature and that the air bubbles are trapped in the film. In the case of EHEC-MFC and MFC, the higher viscosity and faster drying may hinder the movement of air bubbles in the surface, since bubbles were not observed in the films which were dried at $23{ }^{\circ} \mathrm{C}$. The bubbles in the EHEC-MFC and MFC films could therefore be partially explained by the change or stability in the viscosity when the temperature of the solution increased and/or evaporation of liquid occurred.

EHEC-MFC solutions were dried on a glass plate in order to see whether the substrate or drying temperature affected the formation of air bubbles, especially in EHEC-MFC samples with a ratio of 25:75 (Fig. 5). Air bubbles still occurred and the quantity of air bubbles changed according to the composition of the solution in a manner similar to that seen when the samples were dried at $50{ }^{\circ} \mathrm{C}$. The quantity of air bubbles was highest in EHEC-MFC samples with a ratio of $25: 75$ at both $70{ }^{\circ} \mathrm{C}$ and $100{ }^{\circ} \mathrm{C}$. This indicates that a certain EHEC-MFC composition enhances the formation and stabilization of bubbles in the film.

\section{Surface characterization}

Figure 6 shows the AFM topography and phase images of EHEC-MFC, EHEC-methyl nanocellulose and methyl nanocellulose-MFC films with a ratio of 25:75. The fibrillar structure of MFC is clearly visible in all the images of samples containing MFC (Fig. 6a, $\mathrm{b}$, e-h). In contrast, the EHEC-methyl nanocellulose films appear smoother than the films containing MFC

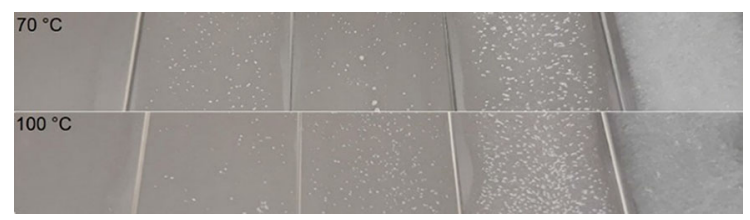

Fig. 5 EHEC-MFC films dried on a glass plate at $70{ }^{\circ} \mathrm{C}$ and $100{ }^{\circ} \mathrm{C}$. From the left: pure EHEC, EHEC:MFC with ratios of 25:75, 50:50 and 25:75, and pure MFC
(Fig. 6c, d), which was confirmed by roughness measurements (Table 1). Small globular aggregates tens of nanometers in diameter were observed in the EHEC-MFC samples dried at $50{ }^{\circ} \mathrm{C}$ but not in the samples dried at $23{ }^{\circ} \mathrm{C}$. The fibrillar structure of MFC was observed in the methyl nanocellulose-MFC film, but the granular structures visible in the EHEC-MFC film were not observed with methyl nanocellulose. This may be due to an increase in particle size of EHEC at higher temperatures in aqueous solutions (Lyytikäinen et al. 2019) or a better compatibility between the methyl nanocellulose and EHEC than between the MFC and EHEC. When the EHEC-MFC films were dried at $23{ }^{\circ} \mathrm{C}$, MFC fibrils were clearly visible as in the EHEC-MFC films dried at $50{ }^{\circ} \mathrm{C}$. EHEC is possibly present as aggregates.

The phase images show more detailed structures and small granules were observed covering the methyl nanocellulose-MFC. These may be methyl groups covering the MFC. Similar observations have been made with nanofibrillated cellulose grafted with poly(glycidyl methacrylate) (Littunen et al. 2011).

PeakForce QNM measurements were performed for the four aforementioned film compositions as well. Sample films thickness was in the range of tens of micrometers. Thus, sufficiently high stiffness of cellulosic materials allows to assume that the sample thicknesses were enough to eliminate effect of the sample substrate on the PeakForce QNM readings. However, it should be noted that microstructure of samples such as voids and nanoparticles have an effect on the PeakForce QNM measurements. Nanocomposite materials containing nanorods demonstrate an effective dissipation of mechanical energy at the interfaces between nanorods and increase of the modulus (Smolyakov et al. 2016). Thus, in the case of MFC-based materials, value of DMT modulus is affected by the structure of the material, interaction of nanofibrils with other component of material.

The modulus values presented in Table 1 show that the samples containing MFC are stiffer than the EHEC and methyl nanocellulose films. Difference in stiffness between EHEC-MFC films may be related to the drying temperatures.

Oxygen barrier properties of the films

The oxygen transmission rate was measured on the films (Table 2) was measured with the conditions of 
Fig. 6 Topography and phase AFM images (tapping mode) of EHEC-MFC (a, b), EHEC-methyl nanocellulose (c, d), methyl nanocellulose-MFC dried at $50{ }^{\circ} \mathrm{C}(\mathbf{e}, \mathbf{f})$ and EHECMFC dried at $23{ }^{\circ} \mathrm{C}(\mathbf{g}, \mathbf{h})$. All samples were in a ratio of $25: 75$
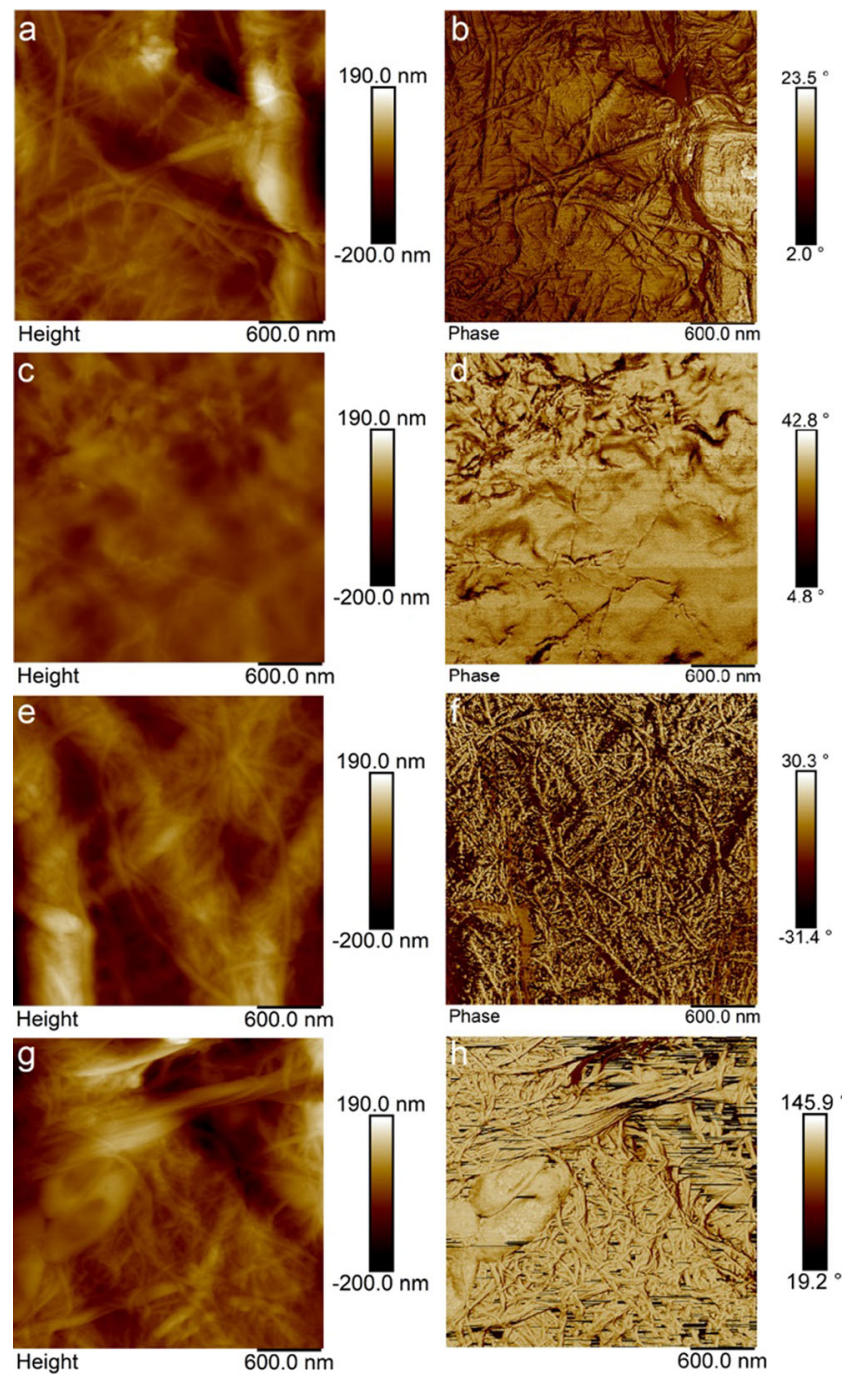

Table 1 Roughness, adhesion and DMT modulus values obtained from PeakForce-QNM measurements

\begin{tabular}{lclc}
\hline Sample & Roughness Rq (RMS) $(\mathrm{nm})$ & Adhesion $(\mathrm{nN})$ & DMT modulus $(\mathrm{MPa})$ \\
\hline EHEC-MFC & $84.5 \pm 13.4$ & $6.8 \pm 0.7$ & $1088 \pm 47$ \\
EHEC-methyl nanocellulose & $35.6 \pm 7.0$ & $6.6 \pm 1.9$ & $904 \pm 118$ \\
Methyl nanocellulose-MFC & $125.6 \pm 46.6$ & $6.3 \pm 1.0$ & $1268 \pm 26$ \\
EHEC-MFC, dried at $23^{\circ} \mathrm{C}$ & $98.7 \pm 26.7$ & $8.1 \pm 0.1$ & $1718 \pm 67$ \\
\hline
\end{tabular}

All the samples were in the ratio of $25: 75$

$23{ }^{\circ} \mathrm{C}$ and $50 \%$ relative humidity (Tayeb et al. 2020). In general, a material is classified as a medium barrier if the oxygen transmission rate is in the range of 6-100 cc/( $\mathrm{m}^{2}$ day) (Mertanen 2015). For the EHEC-
MFC and methyl nanocellulose-MFC films dried at $50{ }^{\circ} \mathrm{C}$ the OTR value decreased with an increasing content of MFC, but the oxygen transmission rate for pure MFC film was high. Similar results have been 
Table 2 Oxygen transmission rate (OTR) of EHEC-MFC films dried at $23{ }^{\circ} \mathrm{C}$ and $50 \% \mathrm{RH}$ and at $50{ }^{\circ} \mathrm{C}$

\begin{tabular}{|c|c|c|c|c|}
\hline \multirow[b]{2}{*}{$\begin{array}{l}\text { Drying temperature } \\
\text { Composition }\end{array}$} & \multicolumn{4}{|c|}{ Oxygen transmission rate $\left(\mathrm{cc} / \mathrm{m}^{2} \cdot\right.$ day $)$} \\
\hline & $\begin{array}{l}23^{\circ} \mathrm{C} \\
\mathrm{EHEC}: \mathrm{MFC}\end{array}$ & $50{ }^{\circ} \mathrm{C}$ & $\begin{array}{l}50^{\circ} \mathrm{C} \\
\text { EHEC:methyl nanocellulose }\end{array}$ & $\begin{array}{l}50^{\circ} \mathrm{C} \\
\text { Methyl nanocellulose:MFC }\end{array}$ \\
\hline 100:0 & $1150 \pm 58$ & $942 \pm 68$ & $942 \pm 68$ & $435 \pm 21$ \\
\hline $75: 25$ & $350 \pm 8$ & $366 \pm 25$ & $741 \pm 20$ & $201 \pm 13$ \\
\hline $50: 50$ & $72 \pm 3$ & $164 \pm 18$ & $604 \pm 18$ & $93 \pm 7$ \\
\hline $25: 75$ & $229 \pm 13$ & $81 \pm 6$ & $321 \pm 15$ & $41 \pm 4$ \\
\hline $0: 100$ & $20 \pm 4$ & $1447 \pm 270$ & $435 \pm 21$ & $1447 \pm 270$ \\
\hline
\end{tabular}

EHEC-methyl nanocellulose and methyl nanocellulose-MFC films were dried at $50{ }^{\circ} \mathrm{C}$. The conditions in the OTR measurements were $23{ }^{\circ} \mathrm{C}$ and $50 \% \mathrm{RH}$

reported by Padberg et al. (2016) for the same MFC grade, and also for less fibrillated MFC. Parallel OTR measurements on the MFC film varied significantly, indicating that dispersant or homogenization is required before film forming. Methyl nanocelluloseMFC films had the lowest OTR values, and the methyl nanocellulose film had the lowest OTR of the pure materials dried at $50{ }^{\circ} \mathrm{C}$. In the EHEC-methyl nanocellulose films a decrease in OTR was observed with increasing content of methyl nanocellulose, but the decrease was not as great as that observed with other composition, possibly because of a better compatibility between methyl nanocellulose and MFC than between EHEC and MFC as indicated by the AFM measurements.

The drying temperature affected the pure MFC films, where an elevated temperature increased the aggregation of cellulose microfibrils (Salmén and Stevanic 2018). The drying temperature also affected the formation of air bubbles. At higher drying temperature, some air bubbles were observed in the MFC films, but the amount of air bubbles was highest in the EHEC-MFC film with a ratio of 25:75. This film had the lowest OTR value. The SEM-image showed that, apart from the air bubbles, the film was uniform and does not affect the barrier properties.

At a lower temperature, the coalescence or removal of the air bubbles was not hindered by the fast drying and the faster increase in viscosity, but, it seems that the air bubbles formed at a higher temperature did not weaken the barrier against oxygen and that the filmforming ability of EHEC or methyl nanocellulose was an important factor. On the other hand, the viscosity measurements suggest that there is an interaction between methyl nanocellulose and MFC at a ratio of 25:75 and between EHEC and MFC at ratios of 75:25 and 50:50. Such an interaction could partly explain the differences between EHEC-MFC at ratios of 50:50 and 25:75 dried at 23 and $50{ }^{\circ} \mathrm{C}$. The interaction between EHEC and methyl nanocellulose at a ratio of 25:75 (Lyytikäinen et al. 2019) could also explain the lower OTR value compared with that of the pure methyl nanocellulose film.

OGR and wetting of the films

OGR measurements were according to the modified ISO 16532-1 standard, where no weight was placed on the oil drop. Oil did not penetrate through the samples in $24 \mathrm{~h}$, regardless of the composition of the film, showing that all the films had a high oil and grease resistance. The oil spread laterally on the EHEC-MFC and EHEC-methyl nanocellulose films, but not on the methyl nanocellulose-MFC film.

The spreading of oil was evaluated by contact angle measurements using rapeseed oil (Fig. 7). On all the surfaces, the contact angle value decreased by nearly $20^{\circ}$ within $1 \mathrm{~s}$. The oil spread almost completely on the EHEC-methyl nanocellulose and EHEC-MFC films within $10 \mathrm{~s}$, only a minor change in the contact angle on the methyl nanocellulose-MFC film was noticed between one and $10 \mathrm{~s}$. The RMS values obtained from the AFM measurements show that the methyl nanocellulose-MFC film had the highest roughness and the contact angle of oil was also the highest for this film. However, the roughness of the hydrophobically modified EHEC-containing films 


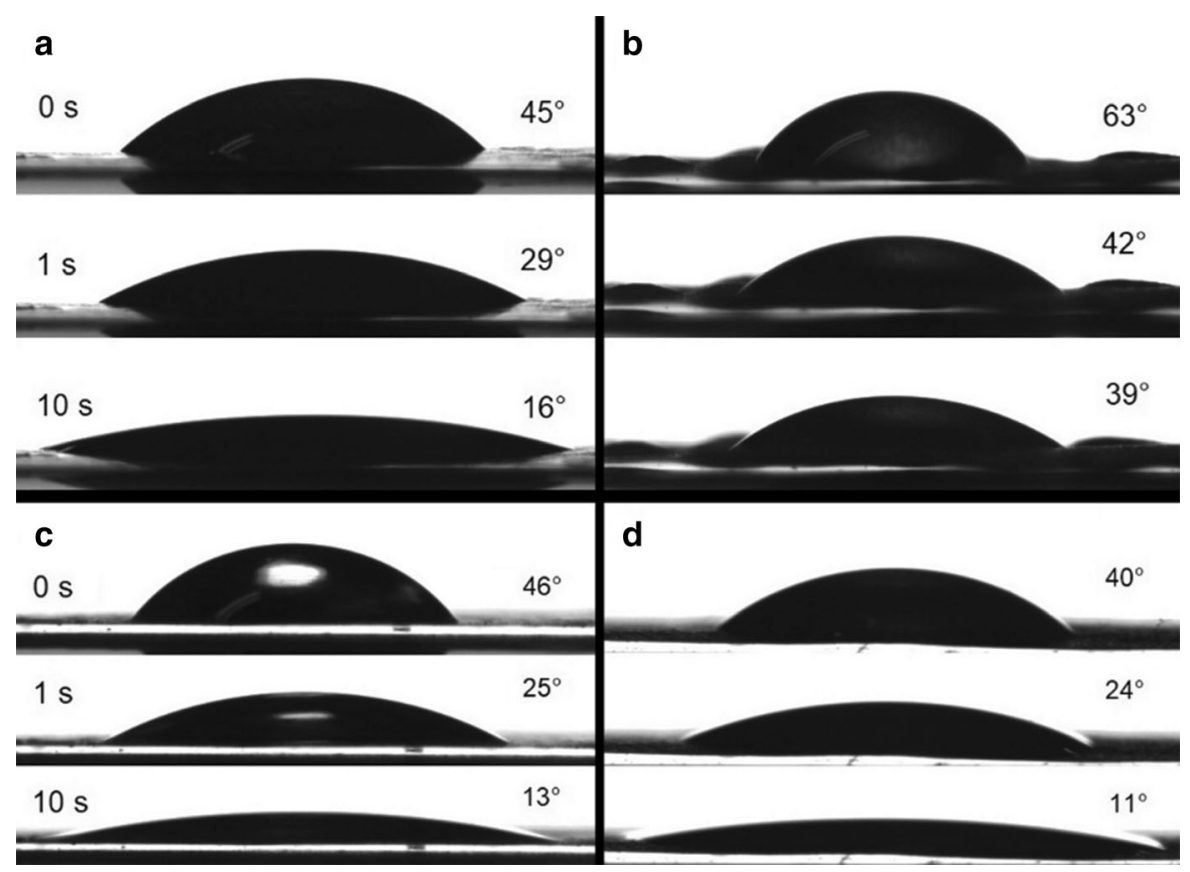

Fig. 7 Spreading of oil on the films one and 10 seconds after applying the oil drop and after applying. EHEC-MFC (a), methyl nanocellulose-MFC (b) and EHEC-methyl nanocellulose (c) films were dried at $50{ }^{\circ} \mathrm{C}$, EHEC-MFC at $23{ }^{\circ} \mathrm{C}(\mathbf{d})$

Table 3 Surface energy and the change in volume and baseline for drops of water, ethylene glycol (EG) and di-iodomethane (DIM) on the surface

\begin{tabular}{|c|c|c|c|c|c|c|c|}
\hline & \multirow{2}{*}{$\begin{array}{l}\text { Surface energy } \\
\mathrm{mN} / \mathrm{m}\end{array}$} & \multicolumn{2}{|l|}{ Water } & \multicolumn{2}{|l|}{ EG } & \multicolumn{2}{|l|}{ DIM } \\
\hline & & $\mathrm{dV} / \mathrm{dt}$ & $\mathrm{dL} / \mathrm{dt}$ & $\mathrm{dV} / \mathrm{dt}$ & $\mathrm{dL} / \mathrm{dt}$ & $\mathrm{dV} / \mathrm{dt}$ & $\mathrm{dL} / \mathrm{dt}$ \\
\hline E25MFC75 & 37.3 & 0.09 & 0.06 & -0.53 & 0.01 & 0.00 & 0.00 \\
\hline $\mathrm{E} 25 \mathrm{Me} 75$ & 33.4 & 0.51 & 0.16 & 0.11 & 0.04 & 0.00 & 0.00 \\
\hline Me25MFC75 & 15.2 & -0.10 & 0.08 & -0.01 & 0.00 & 0.00 & 0.00 \\
\hline $\mathrm{E} 25 \mathrm{MFC} 7523^{\circ} \mathrm{C}$ & 26.1 & 0.08 & 0.02 & -0.06 & 0.01 & 0.00 & 0.01 \\
\hline $\mathrm{Me}$ & 38.6 & 0.05 & 0.15 & 0.00 & -0.01 & 0.00 & 0.00 \\
\hline
\end{tabular}

The change in drop spreading and volume was reported within two seconds after the drop had been placed on the surface. E and Me refer to EHEC and methyl nanocellulose, respectively

varied between the samples but the contact angle of oil was found to behave similarly on the surface.

The spreading of the oil drop in OGR measurements could be explained by dependence of surface energy of the substrates and the behavior of the test liquid (Table 3). EHEC-containing films have a higher surface energy meaning that the wetting of the surface is greater. The drying temperature has an effect since the surface energy was lower in EHEC-MFC films dried in $23{ }^{\circ} \mathrm{C}$. Methyl nanocellulose-MFC films had the lowest surface energy. Using the Lewis acid-base method for surface energy calculation the value was $28 \mathrm{mN} / \mathrm{m}$ for methyl nanocellulose-MFC films, but for the other films the value did not change significantly. The pure methyl nanocellulose film had the highest surface energy although no spreading of the oil was observed during the OGR measurement. Also, the surface energy was lowest with the methyl nanocellulose-MFC film, but correlation was not found in the hydrophobically modified EHEC-containing films. 


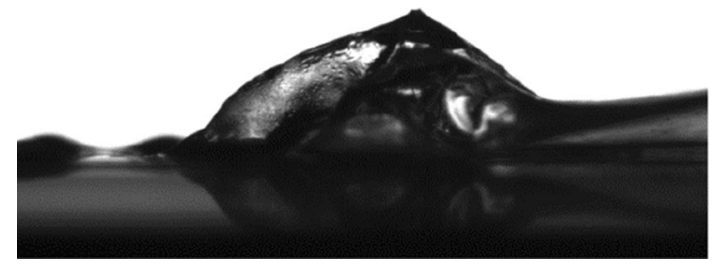

Fig. 8 Swelling of the EHEC-methyl nanocellulose film under a water drop

The di-iodomethane drop remained unchanged on all the surfaces whereas the of water drop changed the most. On the EHEC-methyl nanocellulose film, an increase in drop volume indicated a swelling of the film under the water (Fig. 8). An increase in the baseline of the water i.e. a spreading of the water drop was observed on all the surfaces, especially on the pure methyl nanocellulose and on the EHEC-methyl nanocellulose film, but least on the EHEC-MFC surface dried at $23{ }^{\circ} \mathrm{C}$.

Changes in volume and spreading were observed for the ethylene glycol (EG) drop on the EHECcontaining surfaces. On the EHEC-MFC films, and especially on the film dried at $50{ }^{\circ} \mathrm{C}$, the EG drop was absorbed by the film. On the EHEC-methyl nanocellulose, the drop volume increased indicating a swelling of the material.

\section{Conclusions}

Films with different compositions of EHEC, MFC and methyl nanocellulose were prepared. The effects on oxygen transmission rate and oil and grease resistance of the composition and drying temperature of the films were studied. Viscosity measurements were conducted in order to confirm the interaction between the components.

Viscosity measurements showed that there was an interaction between the components in the EHECMFC and methyl nanocellulose-MFC compositions, indicated by changes in initial viscosity and in gelation temperature. The interaction between the components could also explain the differences in the amount of air bubbles formed in the films during drying and in the OTR results for EHEC-MFC films with ratios of 25:75 and 50:50.

Air bubbles occurred especially in the $75 \%$ MFCcontaining films during drying at higher temperature regardless of the substrate used, indicating that the composition affected the stabilization of the air bubbles. The air bubbles did not weaken the barrier properties of the films and the oxygen barrier increased with increasing addition of MFC. However, MFC itself was a poor oxygen barrier when the film was dried at $50{ }^{\circ} \mathrm{C}$. The oil and grease resistance was over $24 \mathrm{~h}$ for all the samples, but the spreading of oil on the surface varied significantly between the samples.

Acknowledgments Stora Enso Oyj is thanked for financial support of the project. Dr. Anthony Bristow is kindly thanked for the linguistic revision.

Funding Open access funding provided by LUT University.

Open Access This article is licensed under a Creative Commons Attribution 4.0 International License, which permits use, sharing, adaptation, distribution and reproduction in any medium or format, as long as you give appropriate credit to the original author(s) and the source, provide a link to the Creative Commons licence, and indicate if changes were made. The images or other third party material in this article are included in the article's Creative Commons licence, unless indicated otherwise in a credit line to the material. If material is not included in the article's Creative Commons licence and your intended use is not permitted by statutory regulation or exceeds the permitted use, you will need to obtain permission directly from the copyright holder. To view a copy of this licence, visit http://creativecommons.org/licenses/by/4.0/.

\section{References}

Aulin C, Gällstedt M, Lindström T (2010) Oxygen and oil barrier properties of microfibrillated cellulose films and coatings. Cellulose 17(3):559-574

Debeaufort F, Quezada-Gallo JA, Delporte B, Voilley A (2000) Lipid hydrophobicity and physical state effects on the properties of bilayer edible films. J Membr Sci 180(1):47-55

Fukuzumi H, Saito T, Iwata T, Kumamoto Y, Isogai A (2009) Transparent and high gas barrier films of cellulose nanofibers prepared by TEMPO-mediated oxidation. Biomacromolecules 10(1):162-165

Hay WT, Fanta GF, Peterson SC, Thomas AJ, Utt KD, Walsh KA, Boddu VM, Selling GW (2018) Improved hydroxypropyl methylcellulose (HPMC) films through incorporation of amylose-sodium palmitate inclusion complexes. Carbohydr Polym 188:76-84

Hejda F, Solař P, Kousal J (2010) Surface free energy determination by contact angle measurements-a comparison 
of various approaches. In: WDS'10 proceedings of contributed papers, Part III, pp 25-30

Herrera MA, Mathew AP, Oksman K (2017) Barrier and mechanical properties of plasticized and cross-linked nanocellulose coatings for paper packaging applications. Cellulose 24(9):3969-3980

Iotti M, Gregersen ØW, Moe S, Lenes M (2011) Rheological studies of microfibrillar cellulose water dispersions. J Polym Environ 19(1):137-145

Jain S, Sandhu PS, Malvi R, Gupta B (2013) Cellulose derivatives as thermoresponsive polymer: an overview. J Appl Pharm Sci 3(12):139-144

Lavoine N, Desloges I, Dufresne A, Bras J (2012) Microfibrillated cellulose-its barrier properties and applications in cellulosic materials: a review. Carbohydr Polym 90(2):735-764

Littunen K, Hippi U, Johansson LS, Österberg M, Tammelin T, Laine J, Seppälä J (2011) Free radical graft copolymerization of nanofibrillated cellulose with acrylic monomers. Carbohydr Polym 84(3):1039-1047

Lyytikäinen J, Laukala T, Backfolk K (2019) Temperature-dependent interactions between hydrophobically modified ethyl(hydroxyethyl)cellulose and methyl nanocellulose. Cellulose 26(12):7079-7087

Mertanen O (2015) Innovation opportunity mapping-MFC film as a packaging barrier. Master of science thesis, KTH Industrial Engineering and management, Stockholm

Österberg M, Vartiainen J, Lucenius J, Hippi U, Seppälä J, Serimaa R, Laine J (2013) A fast method to produce strong NFC films as a platform for barrier and functional materials. ACS Appl Mater Interfaces 5(11):4640-4647

Padberg J, Bauer W, Gliese T (2016) The influence of fibrillation on the oxygen barrier properties of films from microfibrillated cellulose. Nord Pulp Pap Res J 31(4):548-560

Paunonen S (2013) Strength and barrier enhancements of cellophane and cellulose derivative films: a review. BioResources 8(2):3098-3121

Rodionova G, Lenes M, Eriksen Ø, Gregersen $\varnothing$ (2011) Surface chemical modification of microfibrillated cellulose: improvement of barrier properties for packaging applications. Cellulose 18(1):127-134

Rodionova G, Hoff B, Lenes M, Eriksen Ø, Gregersen Ø (2013) Gas-phase esterification of microfibrillated cellulose (MFC) films. Cellulose 20(3):1167-1174
Salmén L, Stevanic JS (2018) Effect of drying conditions on cellulose microfibril aggregation and "hornification". Cellulose 25(11):6333-6344

Sharma S, Zhang X, Nair SS, Ragauskas A, Zhu J, Deng Y (2014) Thermally enhanced high performance cellulose nano fibril barrier membranes. RSC Adv 4:5136-45142

Smolyakov G, Pruvost S, Cardoso L, Alonso B, Belamie E, Duchet-Rumeau J (2016) AFM PeakForce QNM mode: evidencing nanometer-scale mechanical properties of chitin-silica hybrid nanocomposites. Carbohydr Polym 151:373-380

Solala I, Bordes R, Larsson A (2018) Water vapor mass transport across nanofibrillated cellulose films: effect of surface hydrophobization. Cellulose 25(1):347-356

Spence KL, Venditti RA, Rojas OJ, Pawlak JJ, Hubbe MA (2011) Water vapor barrier properties of coated and filled microfibrillated cellulose composite films. BioResources 6(4):4370-4388

Syverud K, Stenius P (2009) Strength and barrier properties of MFC films. Cellulose 16(1):75-85

Tammelin T, Abburi R, Gestranius M, Laine C, Setälä H, Österberg M (2015) Correlation between cellulose thin film and supramolecular structures and interactions with water. Soft Matter 11:4273-4282

Tayeb AH, Tajvidi M, Bousfield D (2020) Paper-based oil barrier packaging using lignin-containing cellulose nanofibrils. Molecules 25(6):1344

Thuresson K, Lindman B (1997) Effect of hydrophobic modification of a nonionic cellulose derivative on the interaction with surfactants. Phase behavior and association. J Phys Chem B 101(33):6460-6468

Vuoti S, Talja R, Johansson LS, Heikkinen H, Tammelin T (2013) Solvent impact on esterification and film formation ability of nanofibrillated cellulose. Cellulose 20(5):2359-2370

Xia J, Zhang Z, Liu W, Li VCF, Cao Y, Zhang W, Deng Y (2018) Highly transparent $100 \%$ cellulose nanofibril films with extremely high oxygen barriers in high relative humidity. Cellulose 25(7):4057-4066

Publisher's note Springer Nature remains neutral with regard to jurisdictional claims in published maps and institutional affiliations. 